\title{
Direct utilization of kitchen waste for bioethanol production by separate hydrolysis and fermentation (SHF) using locally isolated yeast
}

\begin{abstract}
Kitchen wastes containing high amounts of carbohydrates have potential as low-cost substrates for fermentable sugar production. In this study, enzymatic saccharification of kitchen waste was carried out. Response surface methodology (RSM) was applied to optimize the enzymatic saccharification conditions of kitchen waste. This paper presents analysis of RSM in a predictive model of the combined effects of independent variables $(\mathrm{pH}$, temperature, glucoamylase activity, kitchen waste loading, and hydrolysis time) as the most significant parameters for fermentable sugar production and degree of saccharification. A 100 $\mathrm{mL}$ of kitchen waste was hydrolyzed in $250 \mathrm{~mL}$ of shake flasks. Quadratic RSM predicted maximum fermentable sugar production of $62.79 \mathrm{~g} / \mathrm{L}$ and degree of saccharification $(59.90 \%)$ at the following optimal conditions: $\mathrm{pH} 5$, temperature $60^{\circ} \mathrm{C}$, glucoamylase activity of 85 $\mathrm{U} / \mathrm{mL}$, and utilized $60 \mathrm{~g} / \mathrm{L}$ of kitchen waste as a substrate at $10 \mathrm{~h}$ hydrolysis time. The verification experiments successfully produced $62.71 \pm 0.7 \mathrm{~g} / \mathrm{L}$ of fermentable sugar with $54.93 \pm 0.4 \%$ degree of saccharification within $10 \mathrm{~h}$ of incubation, indicating that the developed model was successfully used to predict fermentable sugar production at more than $90 \%$ accuracy. The sugars produced after hydrolysis of kitchen waste were mainly attributed to monosaccharide: glucose $(80 \%)$ and fructose $(20 \%)$. The fermentable sugars obtained were subsequently used as carbon source for bioethanol production by locally isolated yeasts: Saccharomyces cerevisiae, Candida parasilosis, and Lanchancea fermentati. The yeasts were successfully consumed as sugars hydrolysate, and produced the highest ethanol yield ranging from 0.45 to $0.5 \mathrm{~g} / \mathrm{g}$ and productivity between $0.44 \mathrm{~g} \mathrm{Lï} 1 \mathrm{hï} 1$ and $0.47 \mathrm{~g} \mathrm{Lï} 1 \mathrm{hï} 1$ after 24-h incubation, which was equivalent to $82.061398 .19 \%$ of conversion based on theoretical yield.
\end{abstract}

Keyword: Bioethanol; Enzymatic hydrolysis; Fermentable sugars; Kitchen waste; Response surface methodology (RSM) 